\title{
Efficiency justification for stone-concrete face zone of rockfill dams with reinforced concrete face
}

\author{
Aleksandra Bestuzheva ${ }^{1}$ and Dimitri Gadai ${ }^{2^{*}}$ \\ ${ }^{1}$ Moscow State University of Civil Engineering, Yaroslavskoe shosse, Moscow, Russia \\ ${ }^{2}$ JSC "Institute "Orgenergostroy", Moscow, Russia
}

\begin{abstract}
At present, over 600 dams with a reinforced concrete face are built worldwide; 7 of them are higher than $200 \mathrm{~m}$. However, most of these dams have an inherent disadvantage - face cracking [1, 2, 3], caused by face deformations resulted from the difference in deformation properties of the face and downstream toe. To solve this problem, the authors consider the arrangement of a massive stone-concrete face zone.
\end{abstract}

\section{Introduction}

Stone-concrete is a material produced by grouting of $0.5 \mathrm{~m}$ high crushed stone or gravelcobble backfill 4 using cement-sand grout with mineral non-activated powder added as a plasticizer 5.

Stone-concrete face zone provides lower reinforced concrete face stresses. It allows for arrangement of galleries where instruments can be installed and can be used for face repair by directional cement grouting without reservoir drawdown 6 .

Several stress-strain state calculations are performed to obtain theoretical justification for using stone-concrete in the structure of embankment dams with a reinforced concrete face. The calculations are made by STADAM software developed by A.S. Bestuzheva, Candidate of Engineering Science, associate professor of Hydraulics and Hydraulic Engineering Department of Moscow State University of Civil Engineering (MGSU) National Research University, where soil model developed by L.N. Rasskazov, Doctor of Engineering Science, is implemented based on finite element method combined with local variations method.

The investigation consists of two stages. At the first stage, embankment dam versions with various width face zone and without face zone are compared. When the most costefficient version was found, the influence of face zone rigidity on dam stress-strain state was analyzed for various rigidities.

\footnotetext{
*Corresponding author: dmitri.gadai@mail.ru
} 


\section{Materials and Methods}

The model is based on $100 \mathrm{~m}$ Nahag dam located in the Socialist Republic of Vietnam. Mesh of finite element method consists of 850 nodes and 381 elements with a linear approximation of internal motions, including 34 reinforced concrete face elements and 153 stone-concrete face zone elements. Dam height consists of 17 element layers of various heights. Solved is the plane strain state problem.

Boundary conditions are the absence of any displacements within the dam base and horizontal displacements at its side boundaries. The total number of degrees of freedom is 1646.

The calculation considers that the dam is constructed and loads are applied on a step-bystep basis. 14 calculation steps are considered in total 7. Considered loads are dam element dead weights and upper pond water pressure.

The dam structure consists of the following elements: variable thickness reinforced concrete face, variable thickness stone-concrete face zone, gravel and pebble downstream toe, protective downstream toe including loamy soil, and covering layer of gravel and pebble.

Table 1 shows stress-strain properties of the dam

\begin{tabular}{|c|c|c|c|c|c|c|}
\hline № & Material & $\begin{array}{c}\text { Specific } \\
\text { gravity } \rho, \\
\mathrm{t}^{3}\end{array}$ & $\begin{array}{c}\text { Poisson's } \\
\text { ratio, } v\end{array}$ & $\begin{array}{c}\text { Deformation } \\
\text { modulus E, } \\
\mathrm{MPa}\end{array}$ & $\begin{array}{c}\text { Degree } \\
\text { indicator, } \mathrm{n}\end{array}$ & $\begin{array}{c}\text { Initial shear } \\
\text { modulus } \\
\mathrm{G}_{0}, \mathrm{MPa}\end{array}$ \\
\hline 1 & $\begin{array}{c}\text { Reinforced } \\
\text { concrete }\end{array}$ & 2,40 & 0,20 & 5000 & 1,0 & 2000 \\
\hline 2 & Stone-concrete & 2,06 & 0,22 & 200 & 1,0 & 80 \\
\hline 3 & $\begin{array}{c}\text { Gravel and } \\
\text { pebble } \\
\text { downstream toe }\end{array}$ & 2,00 & 0,27 & 60 & 0,9 & 25 \\
\hline 4 & $\begin{array}{c}\text { Covering layer } \\
\text { of gravel and } \\
\text { pebble }\end{array}$ & 1,90 & 0,27 & 50 & 0,9 & 20 \\
\hline 5 & Loamy soil & 2,10 & 0,35 & 30 & 0,7 & 8,5 \\
\hline
\end{tabular}

The first stage includes calculation of four dam versions which differ by face zone width: Version 1 (no face zone); Version 2 (face zone base width is $37.5 \mathrm{~m}$ ); Version 3 (face zone base width is $74 \mathrm{~m}$, figure 1); Version 4 (face zone base width is $147 \mathrm{~m}$ ). As the investigation result, the following parameters were obtained and analyzed for all dam structure versions: distribution of stresses $\sigma_{\mathrm{y}}$ and $\sigma_{\mathrm{x}}$ inside the dam body, reinforced concrete face and stone-concrete face zone; distribution of primary stresses and displacements $U_{\tau}$ and $U_{n}$ in the reinforced concrete face; changes in deformed dam outlines, displacement $\mathrm{U}_{\mathrm{x}}$ and settlement $\mathrm{U}_{\mathrm{y}}$ both for the dam and for the reinforced concrete face. 


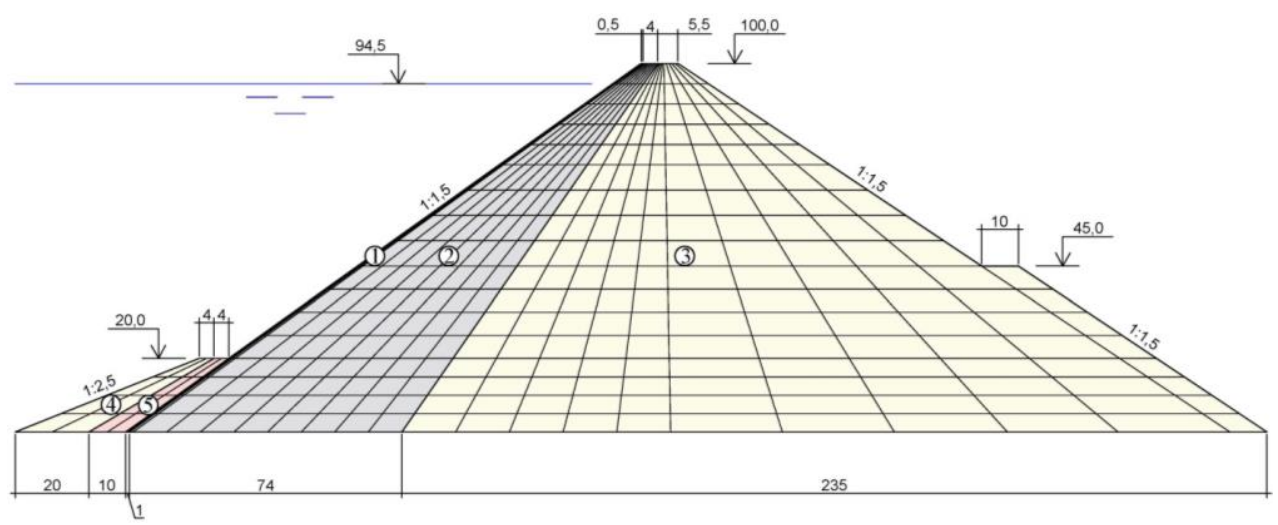

Fig. 1. Dam calculation diagram. Version 3: 1 is reinforced concrete face, 2 is stone-concrete face zone, 3 is gravel and pebble downstream toe soil, 4 is covering layer of gravel and pebble, 5 is loamy soil

For calculations, the following rule of signs is accepted: X-axis is directed horizontally from left to right, Y-axis is directed vertically upwards; displacement is positive if displacement direction is the same with axis direction; tension stresses are positive and compressive stresses are negative.

In all four versions, the highest compressive stresses of the dam body are concentrated within the base under the upper pressure face (figure 2). If a face zone exists, stresses are higher than those within a non-stone-concrete dam. The highest compressive stresses in the stone-concrete base can reach 3.3 MPa. For non-stone-concrete dam, stresses at the same point are lower and reach 2.3 $\mathrm{MPa}$. Note that the obtained highest stresses are within the range of reviewed strength properties of stone-concrete 8 and allow composition selection for casting mixture 9 , based on the required cube strength of stone-concrete.

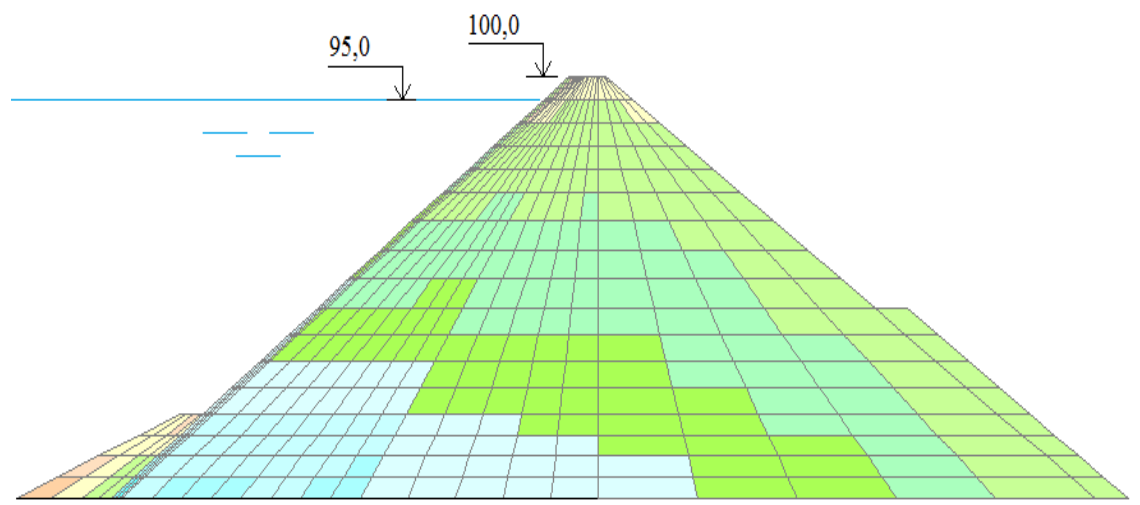

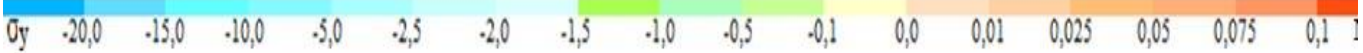

Fig. 2. Stress distribution $\sigma_{\mathrm{y}}$ in the STATDAM software. Version 3 


\section{Results and Discussion}

Based on the obtained face zone stresses and using the Stone-concrete Mixture Composition Selection software 11, casting mixture compositions were selected for stoneconcrete of the three dam versions (table 2).

Table 2. Casting mixture compositions for stone-concrete based on strain-stress state calculations

\begin{tabular}{|c|c|c|c|c|c|}
\hline Version & Stresses in the & \multicolumn{4}{|c|}{ Composition for 1 $\mathrm{m}^{3}$ of stone-concrete } \\
\cline { 3 - 6 } & $\begin{array}{c}\text { sub-screen } \\
\text { zone, MPa }\end{array}$ & $\begin{array}{c}\text { Cement, } \\
\mathrm{kg}\end{array}$ & $\begin{array}{c}\text { Sand, } \\
\mathrm{kg}\end{array}$ & $\begin{array}{c}\text { Mineral } \\
\text { powder, } \mathrm{kg}\end{array}$ & $\begin{array}{c}\text { Water, } \\
1\end{array}$ \\
\hline 1 & -2.3 & \multicolumn{4}{|c|}{ without subscreen zone made of "stone-concrete" } \\
\hline 2 (face zone $37,5 \mathrm{~m}$ ) & -3.3 & 88 & 391 & 250 & 180 \\
\hline 3 (face zone $74 \mathrm{~m}$ ) & -2.9 & 83 & 385 & 250 & 183 \\
\hline 4 (face zone $147 \mathrm{~m}$ ) & -2.6 & 80 & 326 & 250 & 190 \\
\hline
\end{tabular}

The presence of stone-concrete in the face zone causes an increase in stresses $\sigma_{\mathrm{y}}$ by approx. $10 \%$ and wider face zone lead to a gradual decrease in these stresses and their equalization in the horizontal section.

When the water-storage basin is filled, dam horizontal displacement $U_{x}$ is directed towards the lower pond. The greatest horizontal displacement is observed at the height of approx. $1 / 3 \mathrm{H}$ for Version 4 (with wide face zone), the greatest displacement is $16.4 \mathrm{~cm}$, while in Version 1 (w/o face zone), the displacement is $28.4 \mathrm{~cm}$, which is $70 \%$ higher. Version 2 and 3 displacements are between Version 1 and 4 displacements. All greatest displacements are observed in the reinforced concrete face for all versions.

The greatest dam settlements $U_{y}$ are located closer to the upper pond. For Version 1, the greatest settlement is observed at $58 \mathrm{~m}$ elevation - approx. $42 \mathrm{~cm}$. Arrangement of the face zone can decrease settlement in this area, and the greatest settlement will move to the downstream toe area. For a dam with a thin face zone (Version 2), the greatest settlement within the toe is $40 \mathrm{~cm}$, and for a wide one (Version 4) $-29 \mathrm{~cm}$.

Changes in deformed dam outlines, based on calculated settlements and displacements, are shown in figure 3 and figure 4 on the 20:1 scale. The figures clearly show that for Version 1 (w/o face zone), the dam face is deflected almost 2 times more than the version with a wide face zone (Version 4).

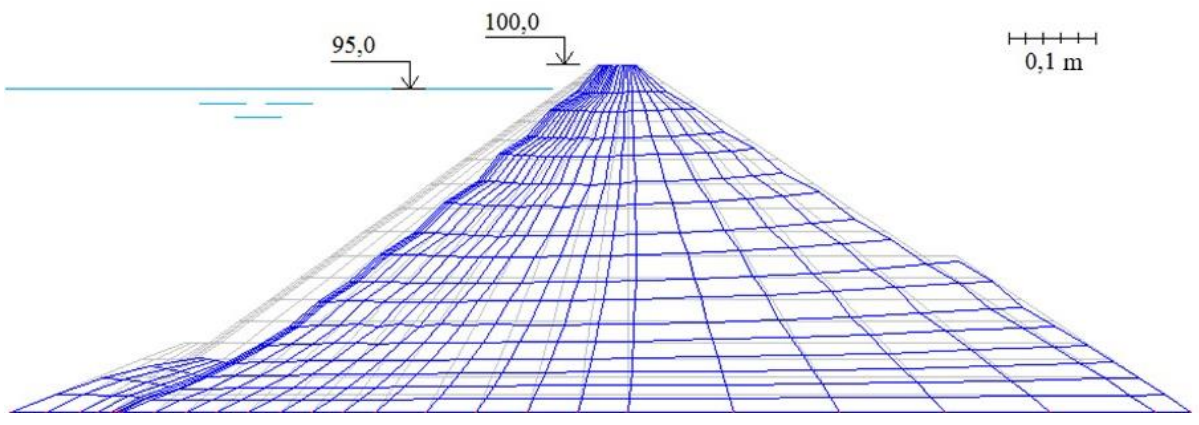

Fig. 3. Dam displacements. Version 1 


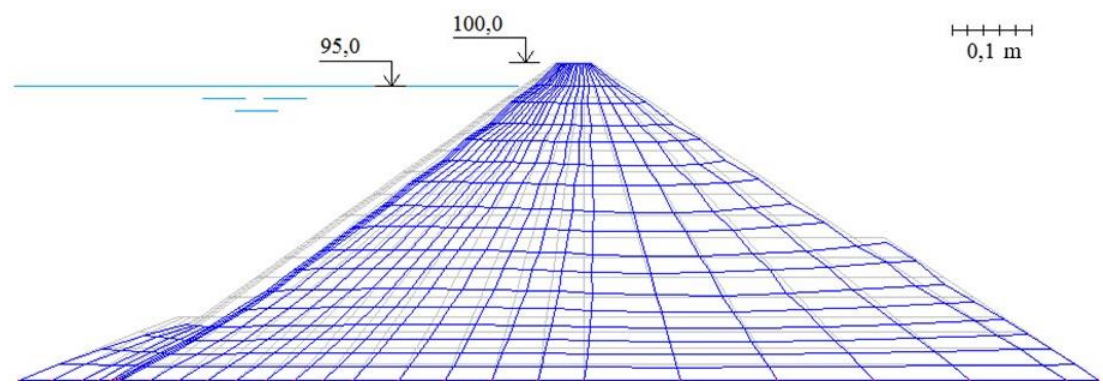

Fig. 4. Dam displacements. Version 4

Primary stresses in the reinforced concrete face are shown in figure 5. The highest compressive stresses are observed for Version 1, while for Versions 2 to 4, the average stresses are 50\% lower. Note that primary tension stresses occur when the face zone is narrow (Version 2) and decrease subsequent to widening of the stone-concrete zone (Versions 3 and 4).

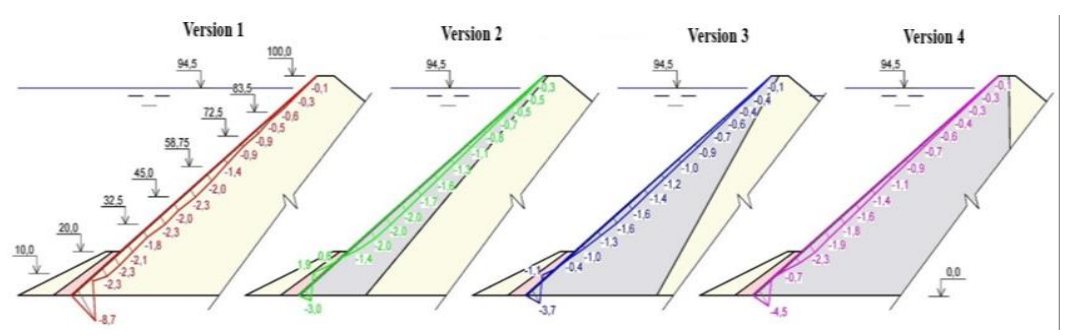

Fig. 5. Comparison between primary stresses in reinforced concrete face, MPa

Greatest face horizontal displacements $U_{x}$ are observed in sections between $32.5 \mathrm{~m}$ and $58.75 \mathrm{~m}$, i.e., between $1 / 3 \mathrm{H}$ and $2 / 3 \mathrm{H}$. For dams without face zone, the greatest displacements reach $28.3 \mathrm{~cm}$ at $32.5 \mathrm{~m}$ elevation. With each subsequent widening of the face zone, displacement is decreased by $15 \%$ on average (Version $2-23.8 \mathrm{~cm}$, Version $3-$ $20.5 \mathrm{~cm}$, Version $4-16.3 \mathrm{~cm})$.

The greatest settlement $U_{y}$, just like horizontal displacements, is observed between 32.5 $\mathrm{m}$ and $58.75 \mathrm{~m}$ elevations and is in the range from $39.6 \mathrm{~cm}$ (Version 1) to $21.7 \mathrm{~cm}$ (Version 4).

Analysis of displacements $U_{\tau}$ showed that widening of stone-concrete face zone leads to greater displacement towards the crest and distribution of displacements throughout the almost entire reinforced concrete face. Greatest displacements towards the crest of $2.3 \mathrm{~cm}$ occur in version with medium face zone thickness (Version 3) at $38.75 \mathrm{~m}$ elevation. Greatest displacements towards the base of $1.7 \mathrm{~cm}$ are observed in Version 1 at $72.5 \mathrm{~m}$ elevation.

Displacements $U_{n}$ are perpendicular to the reinforced concrete face. Displacement from the face towards the face zone and downstream toe is considered as positive displacement. All versions have no negative displacements $U_{n}$ observed, which is reasonable since the face is deflected by upper pond water pressure. The highest displacement $U_{n}$ of $48.7 \mathrm{~cm}$ is measured in Version 1 at $32.5 \mathrm{~m}$ elevation $(1 / 3 \mathrm{H})$. The wider face zone results in an average decrease in displacement by $20 \%$ for each subsequent version, which finally reaches $27.1 \mathrm{~cm}$ for Version 4. 
The obtained reinforced concrete face stresses and displacements for rockfill dam versions with and without stone-concrete face zone are summarized in table 3.

Table 3. Stress-strain state of reinforced concrete face for various widths of stone-concrete face zone

\begin{tabular}{|c|c|c|c|c|c|}
\hline \multirow{2}{*}{ Parameters } & \multirow{2}{*}{ Units } & \multicolumn{4}{|c|}{ Version (width of the face zone) } \\
\cline { 3 - 6 } & & $\begin{array}{c}\text { №1 } \\
(0 \mathrm{~m})\end{array}$ & $\begin{array}{c}\text { №2 } \\
(37,5 \mathrm{~m})\end{array}$ & $\begin{array}{c}\text { №3 } \\
(74 \mathrm{~m})\end{array}$ & $\begin{array}{c}\text { №4 } \\
(147 \mathrm{~m})\end{array}$ \\
\hline Primary compressive stresses & $\mathrm{MPa}$ & $-8,7$ & $-3,0$ & $-3,7$ & $-4,5$ \\
\hline Primary tensile stresses & $\mathrm{MPa}$ & - & 1,9 & 1,1 & - \\
\hline Compressive stresses, $\sigma_{\mathrm{y}}$ & $\mathrm{MPa}$ & $-18,3$ & $-10,8$ & $-11,5$ & $-12,1$ \\
\hline Compressive stresses, $\sigma_{\mathrm{x}}$ & $\mathrm{MPa}$ & $-10,4$ & $-4,7$ & $-5,4$ & $-6,0$ \\
\hline Horizontal displacement, $\mathrm{U}_{\mathrm{x}}$ & $\mathrm{sm}$ & 28,3 & 23,8 & 20,5 & 16,3 \\
\hline Dam settlement, $\mathrm{U}_{\mathrm{y}}$ & $\mathrm{sm}$ & $-39,6$ & $-31,3$ & $-25,2$ & $-21,7$ \\
\hline Displacement $\mathrm{U}_{\tau}$ towards the dam crest & $\mathrm{sm}$ & 0,7 & 1,8 & 2,3 & 1,5 \\
\hline $\begin{array}{c}\text { Displacement } \mathrm{U}_{\tau} \text { towards the downstream } \\
\text { toe }\end{array}$ & $\mathrm{sm}$ & $-1,7$ & $-0,6$ & $-0,2$ & $-0,2$ \\
\hline Displacement $\mathrm{U}_{\mathrm{n}}$ & $\mathrm{sm}$ & 48,7 & 38,8 & 32,4 & 27,1 \\
\hline
\end{tabular}

The results are comparable to the main conclusions outlined in Nguen Than Dat's thesis work written under L.N. Rasskazov's supervision 10, which notes that arrangement of soilconcrete face zone results in smaller dam settlements and displacements. For wide face zones, the stress-strain state of the reinforced concrete face is much better. Based on analysis of data obtained and considering economics, we can recommend the arrangement of medium width face zone (Version 3 ), which is $1 / 5$ base width in this section.

The second investigation stage is calculation of stress-strain state for Version 3 with variable deformation modulus of stone-concrete face zone. 4 cases are reviewed: Case A (stone-concrete deformation modulus $\left.\mathrm{E}_{\mathrm{d}}=200 \mathrm{MPa}\right)$; Case $\mathrm{B}\left(\mathrm{E}_{\mathrm{d}}=300 \mathrm{MPa}\right)$; Case C $\left(\mathrm{E}_{\mathrm{d}}=400 \mathrm{MPa}\right)$ and Case $\mathrm{D}\left(\mathrm{E}_{\mathrm{d}}=500 \mathrm{MPa}\right)$.

Analysis shows that higher rigidity of the face zone results in higher compression stresses $\sigma_{\mathrm{y}}$. For example, for Case A, stress $\sigma_{\mathrm{y}}$ is $-2.9 \mathrm{MPa}$, and for Case $\mathrm{D}$, stress $\sigma_{\mathrm{y}}$ is -4.7 $\mathrm{MPa}$. Note that all these stresses are observed at $0.0 \mathrm{~m}$ elevation where the downstream toe is contacted.

The greatest horizontal displacement $\mathrm{U}_{\mathrm{x}}$ is observed where reinforced concrete face contacts face zone at 2/3 dam height. For the case with the most rigid face zone (Case D), the greatest horizontal displacement is $18.1 \mathrm{~cm}$, which is $13 \%$ smaller than that of the most soft face zone (Case A).

The greatest dam settlement is observed at $2 / 3$ dam height and occurs in downstream toe. The difference between Case A and Case D is only $2 \%$, while the latter's settlement is $37.8 \quad \mathrm{~cm}$. Settlements in Case B and Case $\mathrm{C}$ are of medium magnitude, the same as in the review of horizontal displacements.

The highest compressive stresses $\sigma_{\mathrm{y}}$ in the reinforced concrete face are observed where it contacts the base. Case A - 11.5 MPa, Case D-6.4 MPa. There are no tension stresses.

It was found that versions with more rigid face zone are featured by the development of primary tension stresses along the reinforced concrete face $\sigma_{1}$ (figure 6) up to 2.6 $\mathrm{MPa}$ and positive $\sigma_{\mathrm{x}}$ up to $1.7 \mathrm{MPa}$. 


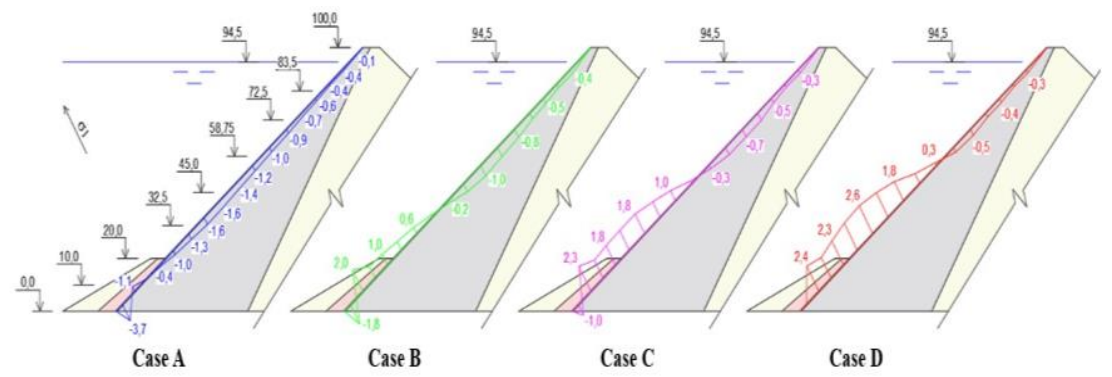

Fig. 6. Comparison between reinforced concrete face stresses $\sigma_{1}$, MPa

A more rigid face zone results in the displacement of reinforced concrete face deformations towards the dam crest. Their general nature is shown in figure $\mathbf{7}$ and figure $\mathbf{8}$ for Cases $\mathrm{A}$ and D.

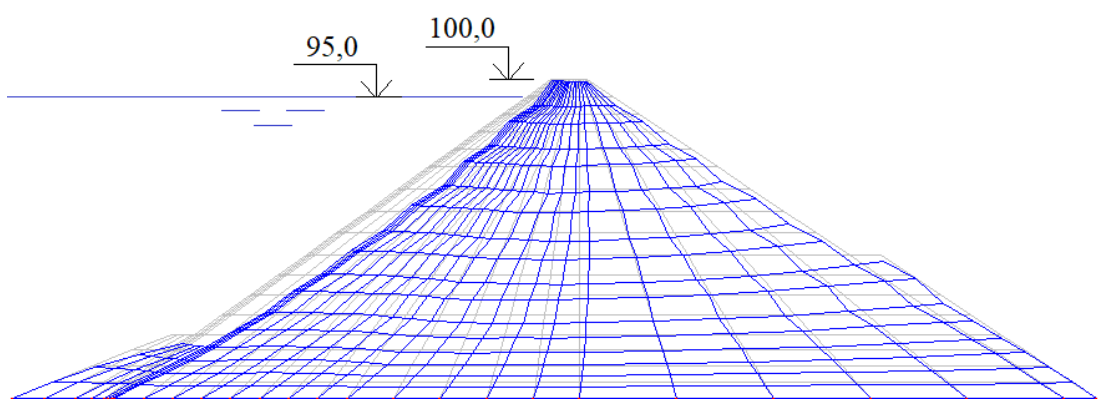

Fig. 7. Dam displacements. Case $A\left(E_{d}=200 \mathrm{MPa}\right)$

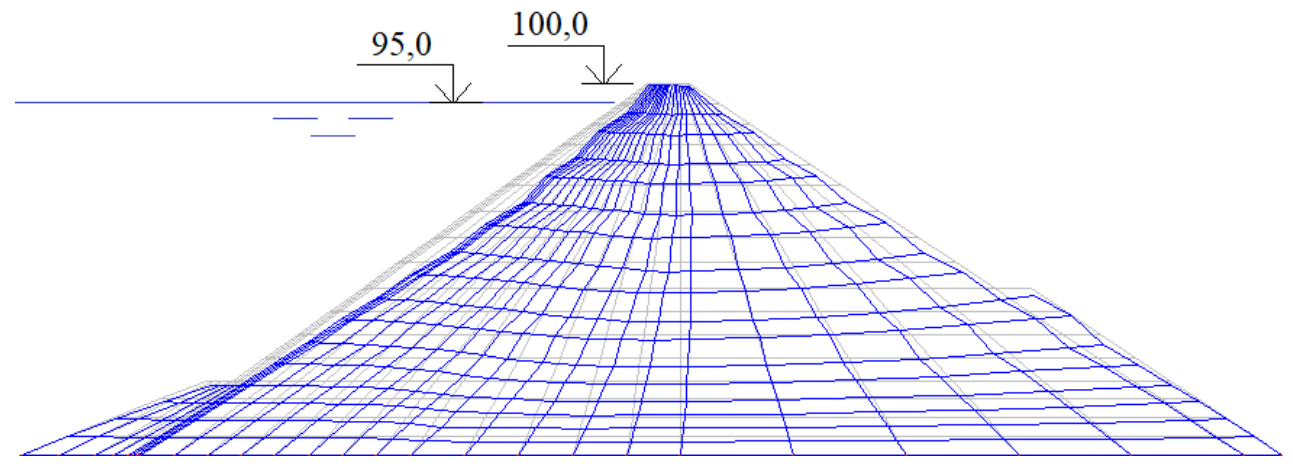

Fig. 8. Dam displacements. Case $\mathrm{D}\left(\mathrm{E}_{\mathrm{d}}=500 \mathrm{MPa}\right)$

Stress-strain state analysis for the reinforced concrete face with various face zone rigidity is summarized in table 4. 
Table 4. Stress-strain state calculation results for various face zone rigidity

\begin{tabular}{|c|c|c|c|c|c|}
\hline Parameters & Units & \multicolumn{4}{|c|}{ Cases } \\
\cline { 3 - 6 } & & $\begin{array}{c}\mathrm{A} \\
\left(\mathrm{E}_{\mathrm{d}}=\right. \\
200 \mathrm{MPa})\end{array}$ & $\begin{array}{c}\mathrm{B} \\
\left(\mathrm{E}_{\mathrm{d}}=\right. \\
300 \mathrm{MPa})\end{array}$ & $\begin{array}{c}\mathrm{C} \\
\left(\mathrm{E}_{\mathrm{d}}=\right. \\
400 \mathrm{MPa})\end{array}$ & $\begin{array}{c}\mathrm{D} \\
\left(\mathrm{E}_{\mathrm{d}}=\right. \\
500 \mathrm{MPa})\end{array}$ \\
\hline Primary compressive stresses & $\mathrm{MPa}$ & $-3,7$ & $-1,8$ & $-1,0$ & $-0,5$ \\
\hline Primary tensile stresses & $\mathrm{MPa}$ & 1,1 & 2,0 & 2,3 & 2,6 \\
\hline Compressive stresses, $\sigma_{\mathrm{y}}$ & $\mathrm{MPa}$ & $-11,5$ & $-8,8$ & $-7,3$ & $-6,4$ \\
\hline Compressive stresses, $\sigma_{\mathrm{x}}$ & $\mathrm{MPa}$ & $-5,4$ & $-3,5$ & $-2,6$ & $-2,1$ \\
\hline Tensile stresses, $\sigma_{\mathrm{x}}$ & $\mathrm{MPa}$ & 0,5 & 1,3 & 1,6 & 1,9 \\
\hline Horizontal displacement, $\mathrm{U}_{\mathrm{x}}$ & $\mathrm{sm}$ & 20,5 & 19,3 & 18,6 & 18,1 \\
\hline Dam settlement, $\mathrm{U}_{\mathrm{y}}$ & $\mathrm{sm}$ & $-25,2$ & $-20,9$ & $-19,2$ & $-18,1$ \\
\hline Displacement $\mathrm{U}_{\tau}$ towards the dam crest & $\mathrm{sm}$ & 2,3 & 3,6 & 4,4 & 4,9 \\
\hline $\begin{array}{c}\text { Displacement } \mathrm{U}_{\tau} \text { towards the } \\
\text { downstream toe }\end{array}$ & $\mathrm{sm}$ & $-0,2$ & $-0,1$ & $-0,1$ & $-0,1$ \\
\hline Displacement $\mathrm{U}_{\mathrm{n}}$ & $\mathrm{sm}$ & 32,4 & 28,3 & 26,1 & 25,2 \\
\hline
\end{tabular}

\section{Conclusions}

1. Investigation of stress-strain state for rockfill dams with reinforced concrete face and stone-concrete face zone shows that face zone is favourable for the stress-strain state of the dam and can decrease both peak face compressive stresses and peak face tension stresses. Settlement of a dam with a stone-concrete face zone is decreased by approx. $30 \%$, which, for $100 \mathrm{~m}$ high dam, results in settlement reduced from $41.9 \mathrm{~cm}$ to $29.8 \mathrm{~cm}$, and horizontal displacement is reduced by approx. $40 \%$, from $28.4 \mathrm{~cm}$ to $16.4 \mathrm{~cm}$. Based on the investigation, we recommend using a medium width face zone, which is $1 / 5$ base width in this work.

2. Stress-strain state investigation for rockfill dams with reinforced concrete face and stone-concrete face zone of various rigidity showed that if face zone rigidity is increased, undesired tension stresses $\sigma_{1}$ directed along the face can occur. Changes in reinforced concrete face settlement and displacement are minor.

3. Based on the investigation, we recommend the arrangement of medium width face zone, which is $1 / 5$ dam base width in this work, with deformation modulus $E_{d}=200$ $\mathrm{MPa}$. Material with such properties can be produced by grouting of $20 \ldots 40 \mathrm{~mm}$ crushed limestone with sand-cement mortar with the following composition: cement $=68 \mathrm{~kg}$, sand $=400 \mathrm{~kg}$, and mineral powder $=250 \mathrm{~kg}$ for $1 \mathrm{~m}^{3}$ stone-concrete 11 .

\section{References}

1 Arici Y Investigation of the cracking of CFRD face plates. Computers and Geotechnics. No 38 pp.905-916, (2011)

2 Filho $\mathrm{M}$ and Pinto De $\mathrm{P}$ CFRD dam characteristics leaned from experience. International Journal on Hydropower and Dams. No 12 (1) pp.72-76, (2005)

3 Song W, Sun Y and Wang Y Reason analysis and treatment for the 1st phase slab cracking of Shuibuya CFRD. Journal of Hydroelectric Engineering, Vol. 3(27) pp.3337, (2008)

4 Bestuzheva A S and Bukanov G N Stone concrete in dam construction. Hydraulic engineering. 10 pp.34-38, (2016)

5 Bestuzheva A S and Gadai D V Search for optimal composition and an investigation 
of special material for the near-face zone of a dam with reinforced concrete face. Power Technology and Engineering. 52(6) pp.660-668 references. (2019)

6 Bestuzheva A S and Gadai D V The search for methods of factor analysis for an optimal design of earth-fill dams with stone-concrete support zone. Power Technology and Engineering. 51(4) pp.385-389, (2017)

7 Gadai D The use of stone-concrete in the construction of rockfill dams with a reinforced concrete face. Dissertation of the Candidate of Technical Sciences (Moscow: Moscow State University of Civil Engineering) p.198, (2019)

8 Bestuzheva A S, Gadai D V and Sadekov R M (2018) Stone-concrete - material for rockfill dam face zone. IOP Conf. Series: Materials Science and Engineering. Vol. 365032024.

9 Bestuzheva A S, Tsipursky I L and Gadai D V Stone concrete: composition design and preparation technology. Power Technology and Engineering. 54 (1) pp.18-22, (2020)

10 Nguyen T D stress-strain state of rockfill dams with reinforced concrete faces. Dissertation of the Candidate of Technical Sciences (Moscow: Moscow State University of Civil Engineering) p.264, (2004)

11 Bestuzheva A S and Gadai D V Selection of the composition of the mixture for stone concrete. (Russian Federation. Certificate of state registration of a computer program) №2019611162 P 1., (26.12.2018) 